www.jmscr.igmpublication.org

Impact Factor (SJIF): 6.379

Index Copernicus Value: 79.54

ISSN (e)-2347-176x ISSN (p) 2455-0450

crossrefDOI: https://dx.doi.org/10.18535/jmscr/v6i12.188

Journal Of Medical Science And Clinical Research

IGM Publication

An Official Publication of IGM Publication

\title{
Surveillance of urinary tract infections and its Management in the elderly
}

\author{
Authors
}

\section{Suren Kumar Das ${ }^{1}$, Swayam Prabha Sahoo ${ }^{2}$, Debabrata Kumar Sabat ${ }^{1}$}

${ }^{1}$ Department of Urology, IMS and SUM Hospital, Siksha O Anusandhan University,

K 8, Kalinga Nagar, Bhubaneswar-751003, Odisha, India

${ }^{2}$ Medical Research Laboratory, IMS and SUM Hospital, Siksha O Anusandhan University, K 8, Kalinga

Nagar, Bhubaneswar-751003, Odisha, India

*Corresponding Author

Dr Debabrata Kumar Sabat

Associate Professor, Dept of Urology, IMS and SUM Hospital, Bhubaneswar-751003, Odisha, India

Email:debabrat78@gmail.com

\begin{abstract}
s
Urinary tract disease (UTI) is the most widely recognized contamination and the main source of bacteremia in the older. With expanding age the female to male proportion diminishes and UTI turns out to be practically half as incessant in men contrasted with ladies. Noteworthy bacteriuria exists in about $40 \%$ of standardized ladies. In any case, asymptomatic bacteriuria is neither the reason for dreariness nor related with a higher death rate and in this manner ought not be dealt with. Symptomatic contamination in ladies without entangling factors is frequently caused by E. coli and might be treated with 3 or multi day regimens of trimethoprim-sulfamethoxazole or fluoroquinolones $(F Q)$. Within the sight of indications of upper tract contamination or confusing elements, pee culture is obligatory and will identify different as well as safe microorganisms much of the time. Exact treatment must be adjusted by the affectability once settled and ought to be controlled for no less than 10 days. The majority of the patients over 65 and for all intents and purposes all patients over 80 present either with general debility or diabetes or different factors, for example, bladder surge hindrance or irregular bladder work and must be considered as giving confused UTI. Inhabiting catheters ought to be expelled if conceivable, generally be changed.

Keywords: Urinary tract infection, bacteriuria-elderly.
\end{abstract}

\section{Introductions}

Urinary contaminations have a high pervasiveness in youthful, explicitly dynamic ladies where they are 30 to multiple times more continuous than in men, however they are additionally increasingly regular in the age aggregate more than 65 years. In the last the clinical introduction much of the time won't be run of the mill and symptomatic and remedial procedures must be adjusted to this age gathering, as unrevealed disease might be incredibly hurtful however overtreatment may likewise be a reason for avoidable reactions and expenses. The present article surveys ongoing writing and gives brief data for the work-up and the board of urinary diseases. Urinary tract contaminations (UTI) are the most widely recognized reason for intense diseases in nursing home inhabitants and the most well-known reason 
for bacteremia in organized and network abiding seniors, 10 to $30 \%$ of which will be deadly. They may prompt numerous fundamental inconveniences, for example, renal and perirenal abscesses, pyonephrosis and scattered contaminations (endocarditis, meningitis and osteomyelitis) ${ }^{(1)}$. With age the female to male proportion will in general decline and in geriatric patients disease is in any event half as successive in men contrasted with ladies. Bacteriuria can be identified in over $20 \%$ of ladies and over $10 \%$ of men beyond 65 years old, and these prevalences ascend to 30- half and 20-30\%, separately, in the systematized old. The nearness of microscopic organisms in an effectively gathered pee example is called bacteriuria and is considered as noteworthy when there are in excess of 100000 state framing units (C.F.U.) per $\mathrm{ml}$, that is, more than normally because of tainting from the front urethra. Asymptomatic bacteriuria alludes to critical bacteriuria in a patient without manifestations. Cystitis is the term given to the disorder including dysuria, recurrence, desperation and at times suprapubic delicacy, yet notice that the nonappearance of upper tract indications in no way, shape or form bars upper tract contamination. The last is regularly described by flank torment and additionally delicacy and fever with or without lower tract indications. Backslide depicts the repeat of bacteriuria with the equivalent tainting microorganism, while reinfection is caused by an alternate one. The terms of "interminable urinary disease" alluding to the tirelessness of the slips after treatment and "incessant pyelonephritis" with changes in the kidneys due just to contamination are not satisfactory. Longitudinal investigations have appeared unending bacteriuria is in certainty irregular and the primary term is therefore regularly utilized basically for repetitive contamination. Then again pathologic portrayals can't separate between changes in the kidney because of incessant disease, constant impediment, pain relieving, hypokalemic or uric corrosive nephropathy ${ }^{(2)}$.

\section{Materials and Methods}

Urinary dipsticks can distinguish pyuria by a positive leukocyte esterase test or the nearness of microscopic organisms by the discovery of nitrite which is delivered by most uropathogens from urinary nitrate, yet the last might be dishonestly negative. Pee microscopy plainly recognizes the nearness of white platelets or microorganisms, yet the lab analysis is generally founded on pee culture. In a midstream clean catch or a straight catheter example in ladies 105 C.F.U./ml are considered as being critical, just as 103 C.F.U./ml in similar examples or a condom catheter example in men. A suprapubic desire example is huge for disease on the off chance that it offers ascend to 102 C.F.U./ml (1).

\section{Results}

The nearness of pyuria and huge bacteriuria in youthful grown-ups demonstrates UTI and doctors traditionally recognize upper from lower tract disease based on clinical manifestations and signs, and the nearness or nonappearance of a fundamental provocative reaction. In the older this methodology ought to be modi fied (Fig. 1). Asymptomatic bacteriuria mirrors a poor general wellbeing status yet isn't the reason for expanded dismalness or mortality. Treatment neither abatements the predominance of bacteriuria, nor the recurrence of symptomatic scenes, it doesn't enhance self-restraint or perpetual genitourinary manifestations and has no impact on mortality, yet it might be hurtful due to the unfriendly impacts of the medications utilized and may instigate antimicrobial opposition in repetitive contamination prompting expanded expenses of social insurance ${ }^{(3)}$. Asymptomatic bacteriuria along these lines ought not be dealt with. Symptomatic UTI mirrors the new beginning of limiting side effects and must be dealt with. Be that as it may, restorative methodologies need to consider the nearness or nonappearance of confusing components. When all is said in done UTI is considered as being entangled on the off chance that it happens in pregnant ladies, kids, 
men or old ladies or within the sight of run of the mill upper tract side effects ${ }^{(4)}$. All the more explicitly either broad debility or practical unsettling influences prompting bladder outpouring obstacle (obstruction, disease of urinary tract, bladder trabeculation, prostate hypertrophy or malignant growth and uterine prolapse) or to anomalous bladder work (stroke, dementia, medical procedure for uterine or rectal disease) are confusing elements in geriatric patients ${ }^{(5)}$. Since these variables are amazingly visit in the old, a few creators propose considering UTI as entangled in every single old patient ${ }^{(6)}$.

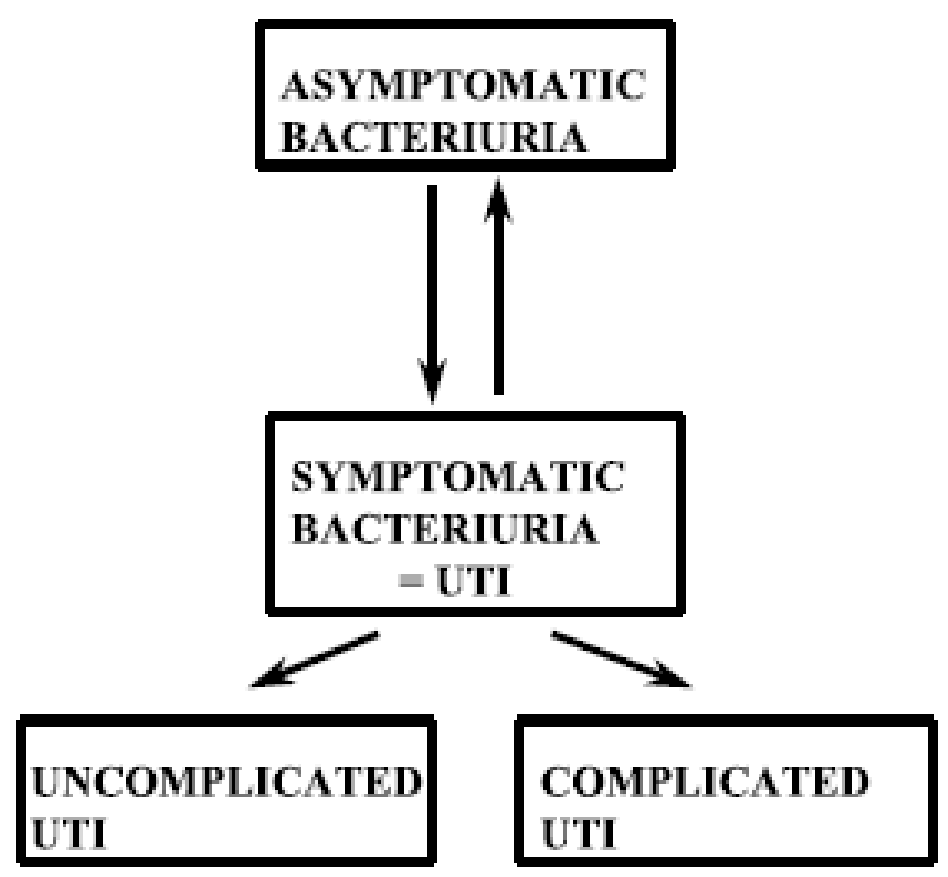

Fig. 1 Classification of UTI in the elderly: distinction between asymptomatic and symptomatic bacteriuria and complicated versus uncomplicated UTI, rather than lower and upper tract infection.

WOMEN

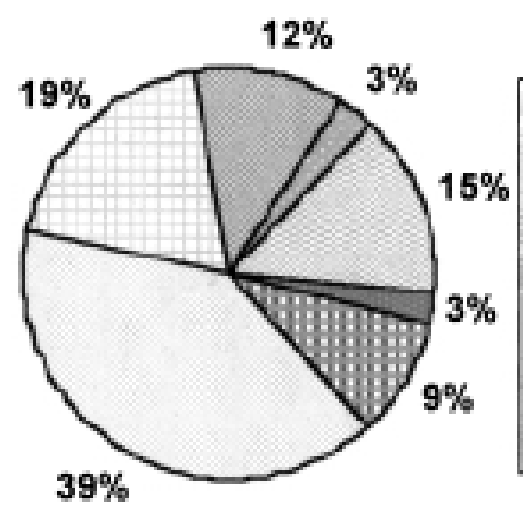

\section{MEN}

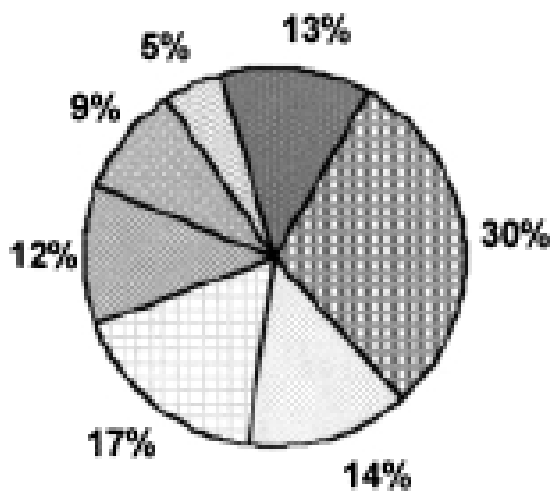

Fig. 2 Most common isolates in elderly people: note the relative importance of mixed infections in both sexes and the high prevalence of gram-positive microorganisms in men 


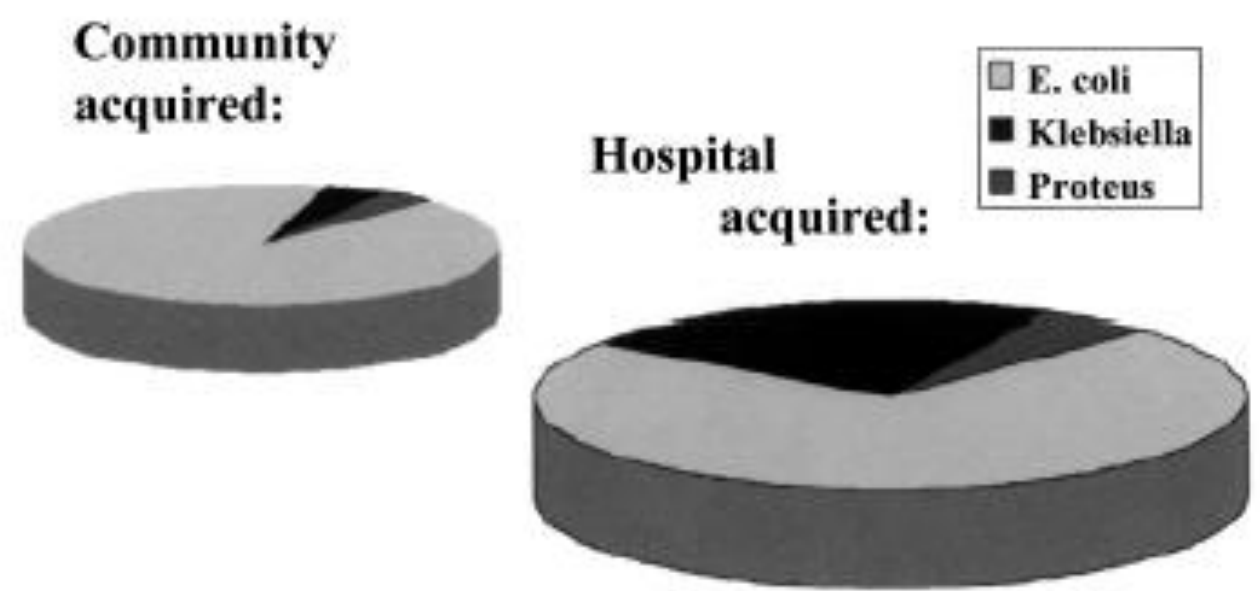

Fig. 3 Uropathogens in community-acquired and hospital-acquired infections: increasing importance of Klebsiella spp.

\section{Discussion}

Clean methods, hydration and fermentation of the pee might be valuable, yet are regularly hard to acquire and their viability has not been demonstrated. Urinary analgesics ought not be utilized as viable anti-infection agents will quickly assuage indications. The adequacy of nearby estrogens has been exhibited in the counteractive action of intermittent UTI in postmenopausal ladies $^{(8)}$, most likely by reestablishing lactobacilli in the vaginal verdure, yet the consistence to this sort of treatment is generally low since around $30 \%$ of patients stop the treatment. In this way, anti-infection agents remain the foundation in the treatment of UTI. The decision of treatment ought to be founded on a negligible impact on vaginal and colonic vegetation, high urinary fixation and ease $^{(6)}$. Uncomplicated UTI might be treated with trimethoprim $200 \mathrm{mg}$ twice every day. The relationship of trimethoprim $160 \mathrm{mg}$ with sulfamethoxazole $800 \mathrm{mg}$ twice day by day is regularly utilized despite the fact that there are questions about the higher viability and reactions might be expanded. An option would be ciprofloxacin $250 \mathrm{mg}$ two times every day. Systematized patients ought to be treated for no less than 7 days. Ciprofloxacin at higher portions (500 mg orally or $200 \mathrm{mg}$ intravenously two times per day) is a decent decision in confused UTI, which may likewise be treated with amoxicillin- clavulanate, aztreonam and aminosides. Drawn out treatment for something like ten days is required. These exact medications may in this manner must be adjusted based on the affectability example of the segregated microorganism. Adjustment to the renal capacity is constantly justified in the old and creatinin leeway must be determined as plasma creatinin is anything but a substantial marker of renal capacity in this age gathering. On the off chance that the underlying treatment has been administrated intravenously, it ought to be changed to oral anti-infection agents when the patient has reacted and can endure oral admission. This change is anything but difficult to perform with fluoroquinolones, for example, ciprofloxacin.

\section{Conclusions}

Urinary tract contaminations are the most wellknown gathering of diseases in the standardized older and may prompt genuine confusions. To maintain a strategic distance from unnecessary symptoms and development of anti-microbial safe strains, in any case, satisfactory administration is vital. Asymptomatic bacteriuria is visit, yet ought not be dealt with. The new beginning of side effects spurs research center tests to affirm the determination of UTI and the sort and term of anti-infection treatment relies upon the qualification among convoluted and 
uncomplicated UTI instead of the confinement to the lower or upper urinary tract. Established multi day regimens will, the majority of the occasions, be inadequate. Research for tests enhancing indicative exactness, for instance by the identification of cytokines in the pee ${ }^{(10)}$, is in progress, yet require further examination.

\section{References}

1. Beier MT (1999) Management of urinary tract infections in the nursing home elderly: a proposed algorithmic approach. Int J Antimicrob Agents 11: 275-284

2. Mandell GL, Bennett JF, Dolin R (eds) (2000) Principles and Practice of Infectious Diseases. Churchill Livingstone (5th edition) vol 1:773-805

3. Nicolle LE (1999) Urinary infections in the elderly: symptomatic or asymptomatic? Int J Antimicrob Agents 11:265268

4. Bogaert M (eds) (1998) Traitment médicamenteux de l'infection urinaire. Folia Pharmacotherapeutica 25(6): 44-46

5. Mc Cue JD (1994) Complicated, recurrent, and geriatric UTI. Clin Focus 8:10-17

6. Gray RP, Malone-Lee J (1995) Review: urinary tract infection in elderly people time to review management? Age Ageing 24:341-345

7. Matsumoto T, Kumazawa J (1999) Urinary tract infection in geriatric patients. Int J Antimicrob Agents 11: 269-273

8. Raz R, Stamm WE (1993) A controlled trial of intravaginal estriol in postmenopausal women with recurrent urinary tract infections. N Engl J Med 329(11): 753-756

9. Sobel JD (1999) Management of asymptomatic candiduria. Int J Antimicrob Agents 11:285-288

10. Nicolle LE, Brunka J, Orr P, Wilkins J, Harding GKM (1993) Urinary immunoreactive interleukin-1a and interleukin- 6 in bacteriuric institutionalized

elderly subjects. J Urol 149: 1049-1053. 